\title{
Research Paper: Effectiveness of Mindfulness-Based Cognitive Therapy on Psychological Aspects of Quality of Life, Depression, Anxiety, and Stress Among Patients With Multiple Sclerosis
}

\author{
Zahra Ghodspour $^{1}$ (D), Mahmoud Najafi ${ }^{1^{*}}$ (D), Issac Rahimian Boogar $^{1}$ (i)
}

1. Department of Clinical Psychology, Faculty of Psychology and Educational Sciences, Semnan University, Semnan, Iran.

\begin{tabular}{|c|c|}
\hline $\begin{array}{l}\text { Use vour device to san } \\
\text { and read the article online }\end{array}$ & Citation: Ghodspour, Z., Najafi, M., \& Rahimian Boogar, I. (2018). Effectiveness of Mindfulness-Based Cognitive Therapy \\
\hline 口情然口 & on Psychological Aspects of Quality of Life, Depression, Anxiety, and Stress Among Patients With Multiple Sclerosis. Journal of \\
\hline Hots & Practice in Clinical Psychology, 6(4), 215-222. http://dx.doi.org/10.32598/jpcp.6.4.215 \\
\hline a & doi $]^{\prime}$ : http://dx.doi.org/10.32598/jpcp.6.4.215 \\
\hline
\end{tabular}

(c) (i) (\$)

Funding: See Page 221

Article info:

Received: 02 Feb 2018

Accepted: 18 May 2018

Available Online: 01 Oct 2018

Keywords:

Mindfulness, Quality of Life, Multiple Sclerosis, Mental distress

\section{ABSTRACT}

Objective: The present study aimed at examining the effectiveness of mindfulness-based cognitive therapy on psychological aspects of Quality of Life, depression, anxiety, and stress in patients with multiple sclerosis.

Methods: This was a quasi-experimental research with pretest-posttest and control group design. A total of 30 members of the MS Society of Semnan City, Iran, was selected by purposive sampling in 2015 and were randomly divided into two groups, i.e. experimental $(\mathrm{n}=15)$ and control $(n=15)$ groups. The experimental group received mindfulness-based cognitive therapy and the control group received no treatment. Before treatment and immediately after treatment, the patients filled in Lovibond psychological distress scale and multiple sclerosis Quality of Life questionnaire. The collected data were analyzed using multivariate analysis of covariance.

Results: The results showed a significant difference between the experimental and control groups in terms of health distress, mental well-being, cognitive function, and role limitations, but no significant difference was found between the two groups in terms of overall Quality of Life. Also there is not any significant difference between the experimental and control group in term of depression, anxiety and stress. Mindfulnessbased cognitive therapy has a significant effect on psychological aspects of Quality of Life, including health distress, mental well-being, role limitations due to emotional problems, and cognitive performance $(\mathrm{P}<0.05)$. However, this effect was not statistically significant on one of the psychological aspects of Quality of Life (overall Quality of Life), depression, anxiety, and stress in patients with multiple sclerosis $(\mathrm{P}>0.05)$.

Conclusion: Mindfulness-based cognitive therapy can improve the psychological Quality of Life of patients with multiple sclerosis.

\section{* Corresponding Author:}

Mahmoud Najafi, PhD

Address: Department of Clinical Psychology, Faculty of Psychology and Educational Sciences, Semnan University, Semnan, Iran

Tel: $+98(23) 33623300$

E-mail:m-najafisemnan.ac.ir 


\section{Highlights}

- The results indicate a significant difference between experimental and control groups with regard to their quality of lives.

- However, there is no significant difference between the experimental and control groups with respect to depression, anxiety and stress after mindfulness-based cognitive therapy.

\section{Plain Language Summary}

Multiple sclerosis is a disease in the nervous system. Many people in our country suffer from this disease. Most of these patients show depressive symptoms, anxiety and stress, and suffer from lower quality of life. In this study, we investigated the effectiveness of cognitive therapy, which is associated with awareness of the mind. We chose one experimental and one control group and compared them before and after the treatment. The results indicate that this treatment reduces depression, anxiety and stress and increases quality of life of the study patients.

\section{Introduction}

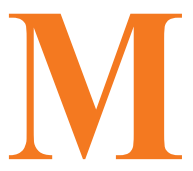

ultiple Sclerosis (MS) is a progressive disease of the central nervous system (Stauffer, 2006). The most common physical symptoms of MS are muscular weakness, urinary incontinence, visual impairment, fatigue, loss of balance, and impaired sense of touch (Arnett, Barwick, \& Beeney, 2010). In addition, patients with MS experience many psychological symptoms. The incidence and prevalence of psychological disorders in these patients are significantly higher than the general population (Beiske et al., 2008).

Depression, as the most prominent and most common psychological disorder (Wallin, Wilken, Turner, \& Williams, 2006), has a life-long prevalence of 50\% and an annual prevalence of $20 \%$ (Sá, 2008). Anxiety is also prevalent among these patients, as research has shown that $34 \%$ of MS patients and $40 \%$ of their parents have experienced high levels of anxiety within an average of 8 months after the diagnosis of the disease (Janssens et al., 2003). There is a relationship between stressful lifestyle and the early onset or relapse of MS (Mitsonis et al., 2008). A wide range of physical and psychological symptoms influence the Quality of Life (QOL), in patients with MS (Zwibel \& Smrtka, 2011).

The loss of social function, as an indicator of QOL, have a high regulatory effect on the relationship between stress and depression symptoms in these patients, in comparison with physical limitations (Kirchner \& Lara, 2011). In addition, other findings suggest that psychosocial factors influence the patients' QOL more se- verely than biological variables (Mitchell, Benito-León, González, \& Rivera-Navarro, 2005).

There are a large number of patients with MS in Iran (World Health Organization, 2008), and a high percentage of whom, have reported low QOL, as well as depression, anxiety, and stress (Dehghan \& Memarian, 2013; Mohammad, Rimaz, Dastoorpour, Sadeghi, \& Majdzadeh, 2014). Almost half of these patients have not received any non-medical treatments so far (Payamani, Nazari, Noktehdan, Ghadiriyan, \& Karami, 2012). Therefore, it is necessary to investigate the effectiveness of non-pharmacological treatments in this population.

One of the most effective treatments to increase the QOL and reduce depression, anxiety, and stress, is MindfulnessBased Cognitive Therapy (MBCT). MBCT has been effective in reducing relapse among patients with major depressive disorder (Omidi, Mohammadkhani, Mohammadi, \& Zargar, 2013), decreasing stress, anxiety and depression and its impact on cardiovascular diseases (Abbott et al., 2014), reducing depression relapse, and improving mental health and QOL, in depressed patients (Godfrin \& Van Heeringen, 2010). Thus, MBCT can be effective in MS patients, as well (Grossman et al., 2010; Levin, Hadgkiss, Weiland, \& Jelinek, 2014; Simpson et al., 2014).

MBCT is a new psychological intervention that was first designed by Segal, Teasdale and Williams (2002) to prevent recurrence of depression. MBCT has been developed based on the integration of cognitive behavioral therapy and mindfulness-based stress reduction therapy by Kabat Zinn and his colleagues (Chiesa \& Serretti, 2010). 
Despite numerous studies available on MBCT, only few has examined the effectiveness of this therapy on the psychological aspects of the QOL, depression, stress and anxiety in patients with MS. Therefore, the present study aimed to evaluate the effectiveness of MBCT on the psychological aspects of the QOL, depression, anxiety, and stress in patients with MS.

\section{Methods}

This study was a quasi-experimental study with pretest and posttest and control group. All female patients with MS, supported by the MS Society of Semnan, Iran, in 2015 , constituted the study population. The samples consisted of 30 members of the MS Society of Semnan City who voluntarily participated in this research, in response to a public call. The study participants were selected by purposive sampling method, and were randomly divided into two groups. The sample size was determined by using Cohen's power analysis table.

Each group consisted of 15 participants. In total, 6 members of the experimental group discontinued the sessions due to physical problems (symptoms after injection, hospitalization, etc.) and 1 participant of the control group, was not willing to complete the questionnaires. These participants were excluded from the study. The inclusion criteria were being female, being 25 to 50 years old, holding diploma degree or above, having past at least 6 months from the diagnosis, being married, and having diagnosed with depression, anxiety, and stress symptom based on the interviews. In addition, the exclusion criteria were suffering from psychotic disorders, taking antipsychotics, receiving at least last 6 months of psychotherapy, using substance and alcohol, and reporting suicidal ideation. Inclusion and exclusion criteria were evaluated based on interviews and self-reports of patients.

After randomly assigning the samples into the experimental and control groups, all the participants completed Lovibond Psychological Distress Scale and Multiple Sclerosis Quality of Life questionnaire, after and before the therapy sessions. The experimental group completed a consent form for participation in the therapy sessions. They attended 2 individual assessment sessions. Information about the research, randomization of study subjects, confidentiality, and the right to withdraw from the study at any time were explained to the participants. Thereafter, the experimental group participated in 8 two-hour sessions of MBCT, on a weekly basis ( 2 months in total).

Multiple Sclerosis Quality of Life health survey-54 (MSQOL- 54) questionnaire contains 54 items and was prepared at the University of California in 1995 (Vickrey, Hays, Harooni, Myers, \& Ellison, 1995). The internal consistency reliability of the scale has been reported as 0.75 to 0.96 and its test-retest reliability coefficient has been reported between 0.66 and 0.96 . This questionnaire consists of Physical Health Composite (PHC) and Mental Health Composite (MHC). The MHC comprises the sum of scores of such components as health distress, overall QOL, psychological well-being, role limitationsemotional, and cognitive function (Vickrey et al., 1995).

In the present study, the MHC was researched. The present study explored MCH. Higher scores of each area suggest better conditions. The reliability and validity of the questionnaire were examined and its Cronbach alpha value was reported 0.96 in Iran (Ghaem, Haghighi, Jafari, \& Nikseresht, 2007). Depression, Anxiety, and Stress Scales-long form (DASS-42) includes three selfreport scales for the assessment of depression, anxiety, and stress (Lovibond \& Lovibond, 1995) This questionnaire was designed by Lovibond and Lovibond (1995), and includes 3 self-report scales for assessing depression, anxiety, and stress. The Cronbach alpha values were found 0.91 for depression scale, 0.4 for the anxiety scale, and 0.84 for the stress scale (Lovibond \& Lovibond, 1995). The reliability and validity of this questionnaire have been evaluated in Iran. Moreover, the Cronbach alpha coefficients were reported 0.94, 0.85, and 0.87 for depression, anxiety, and stress, respectively (Afzali, Delavar, Borjali, \& Mirzamani, 2007).

In protocol of 8-session Mindfulness-based cognitive therapy, the first session is entitled as the autopilot. The second session focuses on coping with the obstacles. The third session focuses on the mindful breathing. The fourth session discusses about living at the moment. The fifth session is dealt with authorized presence. The sixth session explains that thoughts are not facts. The seventh session is about best self-care, and the eighth session focuses on applying learnt items in negative mood states. Segal et al. (2002) are the founders of this treatment method, which was translated into Persian (Mohammadkhani \& Khanipour, 2011). We did not make any changes in the original protocol.

The obtained data were analyzed using descriptive and inferential statistics. In order to examine the difference between the experimental and control groups in pretest and posttest, Multivariate Analysis of Covariance (MANCOVA) was used. All analyses were done in SPSS. 


\section{Results}

A total of $30 \mathrm{MS}$ patients (15 patients in the experimental group and 15 in the control group) participated in this study. Six members of the experimental group and 1 from the control group were excluded from the study. The mean and standard deviation of the mean age participants' age were 36 and 6 years, respectively. Mean \pm SD age of participants was $36 \pm 6$. Of all, $62.5 \%$ of the patients held Diploma and associate degree, and $33.3 \%$ of them BA and MA. About $70 \%$ of the participants were homemakers and $30 \%$ employed. Also, $73.9 \%$ of the participants were relapsing-remitting patients, $8.7 \%$ of them suffered from primary progressive disease type, $13 \%$ of them suffered from secondary progressive MS type, and $4.3 \%$ of them had progressive-relapsing MS. The descriptive indexes pertaining to the psychological aspects of QOL are presented in Table 1. The descriptive statistics regarding depression, anxiety, and stress in pretest and posttest are presented in Table 2 .

MANCOVA was used to evaluate the effectiveness of MBCT in the QOL of patients with MS. Box's test has been used to examine the homogeneity of covariance matrices and Levene's test was used to explore test if the samples have equal variances. Box's test results indicate that this assumption has been met $(\mathrm{F}=0.53 ; \mathrm{P}>0.92)$. Levene's test results also showed that the assumption of the equality of variances has been met in the following subscales: health distress $(\mathrm{F}=1.54 ; \mathrm{P}>0.22)$, well-being $(\mathrm{F}=0.53 ; \mathrm{P}>0.92)$, role limitations $(\mathrm{F}=0.33 ; \mathrm{P}>0.56)$, cognitive function $(\mathrm{F}=1.2 ; \mathrm{P}>0.28)$, and overall $\mathrm{QOL}$ $(\mathrm{F}=0.00 ; \mathrm{P}>0.99)$. The results of MANCOVA showed that MBCT had a significant impact on at least one psychological aspect of QOL in MS patients (Wilks's lamb$\mathrm{da}=0.2, \mathrm{~F}=9.33, \mathrm{P}>0.001$ ).

According to Table 3, there is a significant difference between the experimental and control groups, in terms of health distress, mental well-being, cognitive function, and limitations of role, but no significant difference was found between the groups, in terms of overall QOL. MANCOVA was used to evaluate the effectiveness of MBCT in symptoms of depression, anxiety, and stress, among patients suffering from MS. Box's test was used to examine the homogeneity of covariance matrix and the results suggested this assumption was met $(\mathrm{F}=0.37 ; \mathrm{P}>0.89)$.

Levene's test results also showed that the assumption of the equality of variances has been met in these subscales: depression $(\mathrm{F}=0.54 ; \mathrm{P}>0.46)$, anxiety $(\mathrm{F}=1.32$; $\mathrm{P}>0.26)$, and stress $(\mathrm{F}=3.94 ; \mathrm{P}>0.06)$. The results of MANCOVA showed no significant difference between the groups, in terms of depression, anxiety, and stress (Wilks's lambda $=0.89, \mathrm{~F}=0.62, \mathrm{P}>0.61$ ). According to Table 4, there is not any significant difference between the experimental and control groups in terms of depression, anxiety, and stress.

Table 1. Psychological aspects of Quality of Life in patients with MS in the experimental and control group

\begin{tabular}{|c|c|c|c|}
\hline \multirow{2}{*}{ Subscale } & \multirow{2}{*}{ Group } & Pretest & Posttest \\
\hline & & Mean士SD & Mean $\pm S D$ \\
\hline \multirow{3}{*}{ Health distres } & Experimental & $155.55 \pm 158.67$ & $251.11 \pm 120.87$ \\
\hline & & & \\
\hline & Control & $222.85 \pm 119.44$ & $218.57 \pm 119.60$ \\
\hline \multirow{3}{*}{ Psychological well } & Experimental & $157.77 \pm 53.33$ & $242.22 \pm 81.51$ \\
\hline & & & \\
\hline & Control & $281.42 \pm 103.31$ & $272.85 \pm 112.21$ \\
\hline \multirow{3}{*}{ Role limitatior } & Experimental & $66.66 \pm 66.14$ & $215.55 \pm 89.31$ \\
\hline & & & \\
\hline & Control & $164.28 \pm 121.57$ & $122.85 \pm 118.67$ \\
\hline \multirow{3}{*}{ Cognitive funct } & Experimental & $95.55 \pm 78.59$ & $200 \pm 72.11$ \\
\hline & & & \\
\hline & Control & $166 \pm 81.83$ & $146.42 \pm 91.02$ \\
\hline \multirow{3}{*}{ Overall Quality o } & Experimental & $115.55 \pm 47.55$ & $123.71 \pm 41.73$ \\
\hline & & & \\
\hline & Control & $131.9 \pm 47.48$ & $126.42 \pm 54.94$ \\
\hline
\end{tabular}


Table 2. Depression, anxiety, and stress scores in patients with MS in the experimental and control group

\begin{tabular}{|c|c|c|c|}
\hline \multirow{2}{*}{ Subscale } & \multirow{2}{*}{ Group } & Pretest & Posttest \\
\hline & & Mean $\pm S D$ & Mean $\pm S D$ \\
\hline \multirow{3}{*}{ Depression } & Experimental & $16.66 \pm 8.18$ & $13.33 \pm 9.04$ \\
\hline & & & \\
\hline & Control & $12.92 \pm 7.63$ & $12.07 \pm 12.11$ \\
\hline \multirow{3}{*}{ Anxiety } & Experimental & $16.11 \pm 10.31$ & $9.22 \pm 8.12$ \\
\hline & & & \\
\hline & Control & $9.92 \pm 7.68$ & $10.64 \pm 11.26$ \\
\hline \multirow{3}{*}{ Stress } & Experimental & $23 \pm 10.03$ & $17.88 \pm 10.63$ \\
\hline & & & \\
\hline & Control & $14.57 \pm 8.58$ & $15.07 \pm 12.72$ \\
\hline
\end{tabular}

\section{Discussion}

This study aimed to examine the effectiveness of MBCT on depression, anxiety, stress, and Quality of Life in patients with MS. The MANCOVA results showed that MBCT has significantly improved the psychological dimensions of QOL, health distress, mental well-being, cognitive function, and role limitations in patients with MS, but the overall QOL did not improve, significantly. This is consistent with other research findings (Grossman et al., 2010; Simpson et al., 2014; Tavee, Rensel, Planchon, Butler, \& Stone, 2011).
The non-acceptance of illness is a factor that affects health distress in these patients. By raising awareness through the practice of mindfulness and acceptance of experiences without judgment, this treatment helps patients become aware of their thoughts, feelings, and physical sensations, and accept their disease (Crane, 2013). Research findings have shown that MBCT significantly improves the health-related anxiety in patients with hypochondriasis (Williams, McManus, Muse, \& Williams, 2011).

To account for the improvement of psychological wellbeing, mindfulness is considered as the merger of expanded attention and awareness of experience and the

Table 3. MANCOVA results of the comparison of the experimental and control groups in terms of the psychological aspects of Quality of Life

\begin{tabular}{ccccccc}
\hline Variable & Sum of Squares & df & Mean Square & F & Sig. & Eta \\
\hline Health distress & 51610.15 & 1 & 51610.15 & 5.53 & 0.032 & 0.257 \\
\hline Mental well-being & 35266.79 & 1 & 35266.79 & 22.05 & 0.00 & 0.580 \\
\hline Role limitations & 54938.12 & 1 & 54938.12 & 10.482 & 0.005 & 0.396 \\
\hline Cognitive Function & 28965.92 & 1 & 28965.92 & 11.01 & 0.04 & 0.408 \\
\hline Overall Quality of Life & 3081.62 & 1 & 3081.62 & 2.73 & 0.117 & PRACTICE in \\
\hline
\end{tabular}

CLINICAL PSYCH LOGY

Table 4. MANCOVA results of comparing depression, anxiety, and stress between the experimental and control groups

\begin{tabular}{cccccc}
\hline Variable & Sum of Squares & df & Mean Square & F & 0.19 \\
\hline Depression & 76.29 & 1 & 76.29 & 1.80 & 0.20 \\
Anxiety & 93.78 & 1 & 93.87 & 1.69 & 1.65 \\
Stress & 98.03 & 1 & 98.03 & 0.21 \\
\hline
\end{tabular}


reality and this combination leads to optimized self-regulation and psychological well-being (Brown \& Ryan, 2003). Other researchers also concluded that mindfulness has an essential role in mental well-being (Keng, Smoski, \& Robins, 2011).

In explaining the improvement of role limitations due to emotional problems, studies have shown that the QOL in patients with MS is highly associated with neurological disorders, depression, anxiety, everyday life activities, and instrumental activities of daily living (Ionescu et al., 2012). This treatment can be effective in the reduction of depression and anxiety, and thereby, patients' social function will improve (Keng et al., 2011).

Improved cognitive function could be explained through mindfulness, which is related to the learning of mental concentration and awareness of the present moment activity (Crane, 2013). It leads to increased attention and concentration among these patients. Furthermore, few number of the items (2 questions) in overall Quality of Life in MSQOL, can account for the non-significance of this dimension. In addition to these findings, MANCOVA results also showed no significant differences between the experimental and control groups, in terms of depression, anxiety, and stress. This finding is inconsistent with other findings (Grossman et al., 2010; Simpson et al., 2014).

Such inconsistency could be due to therapeutic effects of this treatment that are demonstrated after 2 months, because negative thinking patterns are active in the form of the automatic, old, and sustainable cognitive habits that are often reflected as rumination. The main skill is to learn quitting persistent cognitive habits or avoiding them. The acquisition of these skills needs numerous repetition and practice (Mohammadkhani \& Khanipour, 2011).

A study on MS, concluded that patients should take regular booster sessions, after 2 months, to obtain recovery and remain stable (Grossman et al., 2010). Another study conducted on bipolar patients, showed that MBCT improves symptoms of depression and anxiety when meditation exercises are performed at least 3 times a week or more (Perich, Manicavasagar, Mitchell, \& Ball, 2013). In fact, this treatment requires practice and spending time. In addition, researchers believe that the effectiveness of MBCT can be a function of individual differences. For example, this therapy is two times more effective in subjects with insecure attachment style, than those with secure attachment style (Keng et al., 2011).
Similarly, people with higher initial mindfulness, benefit more from MBCT (Keng et al., 2011). In addition, MBCT is more effective in individuals with a history of depression relapse for 3 or more time, than those with 2 times history of depression (Keng et al., 2011). The implementation of MBCT on patients with headache revealed that not all patients are equally responsive to it. Two-thirds of the patients respond to this treatment and one-third do not. Changes in the patients' cognitive processes is the most important key factor in determining response to treatment (Day, Thorn, \& Rubin, 2014).

Studies on cognitive function of patients with MS have shown that $40 \%$ to $65 \%$ of the sufferers undergo severe cognitive changes. These cognitive changes develop from the initial stages of the disease, progress over time, and exist in all types of MS. These cognitive changes involve memory, information processing, attention and concentration, executive functions, visual perceptual skills, fluency, and general intelligence (Arnett et al., 2010).

All these cognitive processes can affect the correct completion of the questionnaire. In addition to all above factors, because of the multidimensional nature of this disease and involvement of patients' biopsychosocial and financial aspects, the treatment of MS needs a comprehensive system, including medical, psychiatric, and psychological, rehabilitation, and social services. Moreover, the diverse needs of these patients entail such comprehensive services. Because of the interaction between MS aspects, focus on one aspect and neglecting others can reduce the effectiveness of MBCT and may not provide an affordable and effective response (Stepleman, Jump, Shelton, \& Hughes, 2009).

This study showed that health, socioeconomic, and psychological aspects of the disease have been affected. In addition, the small sample size and the presence of measurement error can be considered as other possible reasons for the non-significance of this result. At the end, because the study subjects were married women, thus we recommend caution in generalizing the results to men and single women. Because of limited samples, this treatment has not been performed on a specific type of MS disease. It is suggested that future studies assess the effectiveness of MBCT on more representative samples. In addition, another study limitation is the lack of a follow-up. Further research should consider follow-up of the effectiveness of MBCT treatment.

Mindfulness-based cognitive therapy can improve the psychological aspect of the Quality of Life in patients 
with MS. Therefore, MBCT can be the best psychological treatment for these patients.

\section{Ethical Considerations}

\section{Compliance with ethical guidelines}

All ethical principles were considered in this article. The participants were informed about the purpose of the research and its implementation stages; They were also assured about the confidentiality of their information; Moreover, They were allowed to leave the study whenever they wish, and if desired, the results of the research would be available to them.

\section{Funding}

This research was extracted from first author's MSc. thesis in Faculty of Psychology, Semnan University, (approval code of 98.94.135)

\section{Conflict of interest}

All authors certify that this manuscript has neither been published in whole, nor in part, or being considered for publication elsewhere. The authors have no conflict of interest to declare.

\section{Acknowledgements}

We would like to thank the patients for their participation and collaboration. In addition, We thank the Higher Education Committee of Semnan University.

\section{References}

Abbott, R. A., Whear, R., Rodgers, L. R., Bethel, A., Coon, J. T., Kuyken, W., et al. (2014). Effectiveness of mindfulness-based stress reduction and mindfulness based cognitive therapy in vascular disease: A systematic review and meta-analysis of randomised controlled trials. Journal of Psychosomatic Research 76(5), 341-51. [DOI:10.1016/j.jpsychores.2014.02.012] [PMID]

Afzali, A., Delavar, A., Borjali, A., \& Mirzamani, M. (2007). Psychometric properties of DASS-42 as assessed in a sample of Kermanshah High School students. Journal of Research in Behavioural Sciences, 5(2), 81-92.

Arnett, P. A., Barwick, F. H., \& Beeney, J. E. (2010). Cognitive and affective neuroscience theories of cognition and depression in multiple sclerosis and guillain-barré syndrome handbook of medical neuropsychology. Berlin: Springer.

Beiske, A., Svensson, E., Sandanger, I., Czujko, B., Pedersen, E., Aarseth, J., et al. (2008). Depression and anxiety amongst multiple sclerosis patients. European Journal of Neurology, 15(3) 239-45. [DOI:10.1111/j.1468-1331.2007.02041.x] [PMID]

Brown, K. W., \& Ryan, R. M. (2003). The benefits of being present: mindfulness and its role in psychological well-being Journal of Personality and Social Psychology, 84(4), 822-48. [DOI:10.1037/0022-3514.84.4.822] [PMID]

Chiesa, A., \& Serretti, A. (2010). A systematic review of neurobiological and clinical features of mindfulness meditations. Psychological Medicine, 40(08), 1239-52. [DOI:10.1017/ S0033291709991747] [PMID]

Crane, R. (2013). Mindfulness-based cognitive therapy: Distinctive features. Abingdon: Routledge.

Day, M. A., Thorn, B. E., \& Rubin, N. J. (2014). Mindfulnessbased cognitive therapy for the treatment of headache pain: A mixed-methods analysis comparing treatment responders and treatment non-responders. Complementary Therapies in Medicine, 22(2), 278-85. [DOI:10.1016/j.ctim.2013.12.018] [PMID]

Dehghan, A., \& Memarian, R. (2013). [Abundance of stress, anxiety and depression in multiple sclerosis patients (Persian)]. Alborz University Medical Journal, 2(2), 82-8.

Ghaem, H., Haghighi, A. B., Jafari, P., \& Nikseresht, A. (2007) Validity and reliability of the Persian version of the multiple sclerosis Quality of Life questionnaire. Neurology India, 55(4), 369-75. [DOI:10.4103/0028-3886.33316] [PMID]

Godfrin, K. A., \& Van Heeringen, C. (2010). The effects of mindfulness-based cognitive therapy on recurrence of depressive episodes, mental health and Quality of Life: A randomized controlled study. Behaviour Research and Therapy, 48(8), 738-46. [DOI:10.1016/j.brat.2010.04.006] [PMID]

Grossman, P., Kappos, L., Gensicke, H., D'souza, M., Mohr, D., Penner, I., et al. (2010). MS Quality of Life, depression, and fatigue improve after mindfulness training: A randomized trial. Neurology, 75(13), 1141-9. [DOI:10.1212/ WNL.0b013e3181f4d80d] [PMID] [PMCID]

Ionescu, P., Petrescu, S., Munjev, N., Gheorghe, R., Stoean, M., \& Boanta-Serban, O. (2012). The importance of depression and anxiety level for the functioning and life quality of multiple sclerosis patients. European Neuropsychopharmacology, 22(2), S385. [DOI:10.1016/S0924-977X(12)70598-9]

Janssens, A., Doorn, P., Boer, J., Meche, F., Passchier, J., \& Hintzen, R. (2003). Impact of recently diagnosed multiple sclerosis on Quality of Life, anxiety, depression and distress of patients and partners. Acta Neurologica Scandinavica, 108(6) 389-95. [DOI:10.1034/j.1600-0404.2003.00166.x] [PMID]

Keng, S. L., Smoski, M. J., \& Robins, C. J. (2011). Effects of mindfulness on psychological health: A review of empirical studies. Clinical Psychology Review, 31(6), 1041-56. [DOI:10.1016/j. cpr.2011.04.006] [PMID] [PMCID]

Kirchner, T., \& Lara, S. (2011). Stress and depression symptoms in patients with multiple sclerosis: The mediating role of the loss of social functioning. Acta Neurologica Scandinavica, 123(6), 407-13. [DOI:10.1111/j.1600-0404.2010.01422.x] [PMID]

Levin, A. B., Hadgkiss, E. J., Weiland, T. J., \& Jelinek, G. A (2014). Meditation as an adjunct to the management of multiple sclerosis. Neurology Research International, 2014, 704691. [DOI:10.1155/2014/704691] [PMID] [PMCID] 
Lovibond, P. F., \& Lovibond, S. H. (1995). The structure of negative emotional states: Comparison of the Depression Anxiety Stress Scales (DASS) with the Beck Depression and Anxiety Inventories. Behaviour Research and Therapy, 33(3), 335-43. [DOI:10.1016/0005-7967(94)00075-U]

Mitchell, A. J., Benito-León, J., González, J. M. M., \& Rivera Navarro, J. (2005). Quality of Life and its assessment in multiple sclerosis: Integrating physical and psychological components of wellbeing. The Lancet Neurology, 4(9), 556-66. [DOI:10.1016/ S1474-4422(05)70166-6]

Mitsonis, C. I., Zervas, I. M., Mitropoulos, P. A., Dimopoulos, N. P., Soldatos, C. R., Potagas, C. M., et al. (2008). The impact of stressful life events on risk of relapse in women with multiple sclerosis: A prospective study. European Psychiatry, 23(7), 497504. [DOI:10.1016/j.eurpsy.2008.06.003] [PMID]

Mohammad, K., Rimaz, S., Dastoorpour, M., Sadeghi, M., \& Majdzadeh, S. R. (2014). [Quality of Life and related factors among multiple sclerosis patients (Persian)]. Journal of School of Public Health and Institute of Public Health Research, 11(4), 1-14.

Mohammadkhani, P., \& Khanipour, H. (2011). Mindfulness based cognitive therapies. Tehran: University of Social Welfare and Rehabilitation Science. [PMCID]

Omidi, A., Mohammadkhani, P., Mohammadi, A., \& Zargar, F. (2013). Comparing mindfulness based cognitive therapy and traditional cognitive behavior therapy with treatments as usual on reduction of major depressive disorder symptoms. Iranian Red Crescent Medical Journal, 15(2), 142-6. [DOI:10.5812/ ircmj.8018] [PMID] [PMCID]

Payamani, F., Nazari, A., Noktehdan, H., Ghadiriyan, F., \& Karami, K. (2012). Complementary therapy in patients with multiple sclerosis. Iran Journal of Nursing, 25(77), 12-20.

Perich, T., Manicavasagar, V., Mitchell, P. B., \& Ball, J. R. (2013). The association between meditation practice and treatment outcome in mindfulness-based cognitive therapy for bipolar disorder. Behaviour Research and Therapy, 51(7), 338-43. [DOI:10.1016/j.brat.2013.03.006] [PMID]

Sá, M. J. (2008). Psychological aspects of multiple sclerosis. Clinical Neurology and Neurosurgery, 110(9), 868-77. [DOI:10.1016/j. clineuro.2007.10.001] [PMID]

Segal, Z., Williams, J., \& Teasdale, J. (2002). Mindfulness- based cognitive therapy for depression: A new approach to prevention relapse. New York: Guilford Press.

Simpson, R., Booth, J., Lawrence, M., Byrne, S., Mair, F., \& Mercer, S. (2014). Mindfulness based interventions in multiple sclerosis: A systematic review. BMC Neurology, 14(1), 15. [DOI:10.1186/1471-2377-14-15] [PMID] [PMCID]

Stauffer, M. (2006). Understanding multiple sclerosis. Jackson, Mississippi: University Press of Mississippi.

Stepleman, L. M., Jump, R., Shelton, S. F., \& Hughes, M. D. (2009). Psychological consultation services at a Multiple Sclerosis clinic: A programmatic example. International Journal of MS Care, 11(4), 180-6. [DOI:10.7224/1537-2073-11.4.180]

Tavee, J., Rensel, M., Planchon, S. M., Butler, R. S., \& Stone, L. (2011). Effects of meditation on pain and Quality of Life in multiple sclerosis and peripheral neuropathy: A pilot study. International Journal of MS Care, 13(4), 163-8. [DOI:10.7224/15372073-13.4.163] [PMID] [PMCID]
Vickrey, B., Hays, R. D., Harooni, R., Myers, L. W., \& Ellison, G. W. (1995). A health-related Quality of Life measure for multiple sclerosis. Quality of Life Research, 4(3), 187-206. [DOI:10.1007/BF02260859] [PMID]

Wallin, M. T., Wilken, J. A., Turner, A. P., \& Williams, R. M. (2006). Depression and multiple sclerosis: Review of a lethal combination. Journal of Rehabilitation Research and Development, 43(1), 45-62. [DOI:10.1682/JRRD.2004.09.0117] [PMID]

Williams, M. J., McManus, F., Muse, K., \& Williams, J. M. G. (2011). Mindfulness-based cognitive therapy for severe health anxiety (hypochondriasis): An interpretative phenomenological analysis of patients' experiences. British Journal of Clinical Psychology, 50(4), 379-97. [DOI:10.1111/j.20448260.2010.02000.x] [PMID]

World Health Organization. (2008). Atlas: Multiple sclerosis resources in the world 2008. Geneva: World Health Organization

Zwibel, H. L., \& Smrtka, J. (2011). Improving Quality of Life in multiple sclerosis: an unmet need. The American Journal of Managed Care, 17(Suppl 5), S139-45. [PMID] 